\title{
Attitudes toward withholding antibiotics from people with dementia lacking decisional capacity: findings from a survey of Canadian stakeholders
}

\author{
Gina Bravo ${ }^{1,2^{*}}$, Lieve Van den Block ${ }^{3}$, Jocelyn Downie ${ }^{4}$, Marcel Arcand ${ }^{2,5}$ and Lise Trottier $^{2}$
}

\begin{abstract}
Background: Healthcare professionals and surrogate decision-makers often face the difficult decision of whether to initiate or withhold antibiotics from people with dementia who have developed a life-threatening infection after losing decisional capacity.

Methods: We conducted a vignette-based survey among 1050 Quebec stakeholders (senior citizens, family caregivers, nurses and physicians; response rate 49.4\%) to (1) assess their attitudes toward withholding antibiotics from people with dementia lacking decisional capacity; (2) compare attitudes between dementia stages and stakeholder groups; and (3) investigate other correlates of attitudes, including support for continuous deep sedation (CDS) and medical assistance in dying (MAID). The vignettes feature a woman moving along the dementia trajectory, who has refused in writing all life-prolonging interventions and explicitly requested that a doctor end her life when she no longer recognizes her loved ones. Two stages were considered after she had lost capacity: the advanced stage, where she likely has several more years to live, and the terminal stage, where she is close to death.

Results: Support for withholding antibiotics ranged from $75 \%$ among seniors and caregivers at the advanced stage, to $98 \%$ among physicians at the terminal stage. Using the generalized estimating equation approach, we found stakeholder group, religiosity, and support for CDS and MAID, to be associated with attitudes toward antibiotics.

Conclusions: Findings underscore the importance for healthcare professionals of discussing underlying values and treatment goals with people at an early stage of dementia and their relatives, to help them anticipate future care decisions and better prepare surrogates for their role. Findings also have implications for the scope of MAID laws, in particular in Canada where the extension of MAID to persons lacking decisional capacity is currently being considered.
\end{abstract}

Keywords: Dementia, Decisional incapacity, Advance directive, Infection, Antibiotics, Continuous deep sedation, Euthanasia, Medical assistance in dying (MAID), Survey, Canada

\section{Background}

Lower respiratory tract infections, particularly pneumonia, are common in nursing home residents at later stages

\footnotetext{
*Correspondence: Gina.Bravo@USherbrooke.ca

${ }^{1}$ Department of Community Health Sciences, Faculty of Medicine

and Health Sciences, Université de Sherbrooke, Sherbrooke, Canada

Full list of author information is available at the end of the article
}

of dementia, increasing the risk of discomfort and death in this already frail population1[1-4]. When a person who lacks decisional capacity contracts a life-threatening infection, the decision to initiate or withhold antibiotic therapy most often falls to surrogate decision-makers, typically close family members assisted by healthcare professionals $[5,6]$. Such decisions can be difficult to make, for several reasons. 
First, some patients will not have made their wishes for health care known in advance of loss of capacity [7-10]. Others may have discussed their wishes with their loved ones, and some may have put them in writing, but without being specific about how they want to be treated if they were to develop a life-threatening infection [10]. Second, the extent to which antibiotic therapy significantly improves comfort or prolongs life in these patients is still being debated in the scientific literature [11-13]. Third, antibiotic therapy may be burdensome and cause suffering in itself, often requiring hospitalisation, parenteral administration, adequate hydration for greater efficacy, and restraints to prevent removal of intravenous lines $[11,14,15]$. Concerns about antimicrobial resistance complicate things further [13,16-18], especially in long-term care settings where most people at later stages of dementia are cared for and will ultimately die $[19,20]$. Unless a clear and well-informed advance directive ${ }^{1}$ is available, choosing the best approach to life-threatening infections can thus be challenging, requiring surrogate decision-makers and healthcare professionals to carefully balance complex medical and ethical considerations (e.g., whether antibiotics are medically indicated or futile in the situation; cost-utility issues; whether to accept potential burden caused by treatment; weighing the patient's best interests against patient and family preferences; balancing benefit to the present patient given antibiotics against harm to future patients due to antimicrobial resistance) [16, 21-23].

The widely-endorsed principle of respect for patient autonomy would require decision-makers to follow the patient's goals of care, when these are known and apply to the clinical situation. However, a multitude of factors besides previously expressed wishes have been shown to influence decisions regarding antibiotic therapy, both in practice and when studied through hypothetical scenarios [23-29]. Potentially influential factors include clinical features of the infectious episode; patients' current condition (e.g., illness severity, perceived quality of life, prognosis); families' wishes and beliefs; expected treatment effectiveness and impact on patients' quality of life; ethical considerations as those listed above; and characteristics of care providers (e.g., age, gender, religiosity, training in end-of-life care). Antibiotic use has also been shown to vary across countries, due to differences in legislation, care organization, culture, and staff competences in palliative care [23, 30-33].

\footnotetext{
${ }^{1}$ In this paper, an advance directive (whether legally binding or not) is any document (e.g., a living will) in which a person expresses his or her values, preferences, or goals of care in the event that he or she should become decisionally incapacitated. Such document aims at helping those who could be called upon, in the future, to make health-related decisions on the person's behalf.
}

Past research has thus uncovered determinants of people's attitudes toward starting or withholding antibiotic therapy in the presence of dementia. However, as far as we know, no study has directly compared attitudes across dementia stages and stakeholder groups. Moreover, attitudes toward other options for relieving suffering at the end of life, specifically continuous deep sedation (CDS) and medical assistance in dying (MAID), have rarely been investigated for their associations with attitudes toward the use of antibiotics in the context of dementia.

CDS relieves suffering from refractory symptoms by rendering the patient unconscious until death, whereas MAID involves ending the patient's life through a lethal injection [34]. CDS is considered an ethically acceptable means to relieve suffering when death is imminent, although acceptability is reduced by the possible lifeshortening effects of this medical procedure in situations where artificial nutrition and hydration is forgone $[35,36]$. In patients with dementia and pneumonia, CDS may enhance comfort in the days before death [2, 34, 37]. Still, there is no consensus about the appropriateness of using CDS in advanced dementia patients, whose inability to participate in decision-making makes assessing the intensity of their suffering a challenging task for physicians [38]. MAID is an even more controversial practice, especially in later stages of dementia [39]. At the time the present study was conducted, only three countries (the Netherlands, Belgium and Luxembourg) allowed formerly capable patients to access MAID through a prior written request, provided that they meet the legal requirements.

In Canada, at the time of our study, MAID was legal for those who met the eligibility criteria and procedural safeguards set out in the Criminal Code [40]. Some Canadians with dementia (even as their sole underlying medical condition) could qualify for MAID and some received MAID [41-44]. To be eligible they had to have decisionmaking capacity at the time of provision of MAID and have met the eligibility criteria. ${ }^{23}$ However, many Canadians (including healthcare professionals) were unaware

\footnotetext{
${ }^{2}$ The eligibility criteria were:

- they have a serious and incurable illness, disease, or disability;

- they are in an advanced state of irreversible decline in capability;

- that illness, disease, or disability or that state of decline causes them enduring physical or psychological suffering that is intolerable to them and that cannot be relieved under conditions that they consider acceptable; and

- their natural death has become reasonably foreseeable, taking into account all of their medical circumstances, without a prognosis necessarily having been made as to the specific length of time that they have remaining.

${ }^{3}$ After the study was completed, the Canadian law was amended, removing the requirement that the person's natural death is reasonably foreseeable and allowing a form of advance request for MAID [45]. If a person met the first three eligibility criteria set out above and made a written agreement for the provision of MAID on a specific date in the future, they could receive MAID after losing decision-making capacity.
} 
of this and believed that MAID was entirely inaccessible to people with dementia - wrongly believing that someone with dementia could not both have decision-making capacity and meet the eligibility criteria for MAID.

In the Canadian province of Quebec where our study was conducted, except in emergency situations, if the patient is incapable of giving or refusing consent to care and has not drawn up advance medical directives, a person authorized by law or by a protection mandate ${ }^{4}$ may do so in the patient's place. In the absence of advance medical directives, ${ }^{5}$ consent is given by his or her courtappointed representative (a mandatory, tutor or curator). If the patient is not so represented, consent is given by someone close to the patient (i.e., his or her spouse or partner, an involved relative or friend). The person consenting on behalf of the patient (herein called the surrogate decision-maker) must act in the sole interest of that patient, complying, as far as possible, with any wishes the latter may have expressed [49]. If the incapacitated patient has issued advance medical directives, the healthcare provider is not required to obtain authorization from the patient's surrogate decision-maker. Advance medical directives are binding, which means that healthcare providers who are aware of their existence must comply with them (provided the care is medically indicated in the clinical situation).

Given rapidly changing practices in end-of-life care, and gaps in current knowledge on attitudes toward antibiotics for people with dementia lacking decisional capacity, this study seeks to answer the following three questions: (1) To what extent do different stakeholders support withholding antibiotics from people at later stages of dementia?; (2) Does support vary between dementia stages and stakeholder groups?; and (3) Are stakeholders' sociodemographic characteristics and support for CDS and MAID associated with their attitudes toward antibiotics? Based on past findings $[16,23,25$,

\footnotetext{
${ }^{4}$ A protection mandate is a document in which a person can choose one person or several people (called a mandatory or mandatories) to make decisions on his or her behalf in the event of incapacity and give instructions about health care that he or she wants or does not want [46].

${ }^{5}$ Advance medical directives are another way of expressing one's wishes regarding medical care in the event of incapacity [47]. Created under the Act Respecting End-of-Life Care that legalized MAID in certain circumstances [48], advance medical directives have priority over a protection mandate if both exist and the incapacitated patient is in one of the clinical situations in which they apply: i.e., the patient (1) suffers from a serious and incurable medical condition, and is at the end of life; (2) is in a coma deemed irreversible or in a permanent vegetative state; or (3) has severe dementia with no possibility of improvement. For each situation, the person can accept or refuse five interventions: cardiopulmonary resuscitation, ventilator-assisted breathing, dialysis, and artificial feeding and hydration. For greater access, advance medical directives are filed in a registry held by the Quebec health insurance board (Régie de l'Assurance maladie du Québec). Medical assistance in dying cannot be asked for in advance medical directives.
}

50], we expected lay respondents to be less in favour of withholding antibiotics than healthcare professionals. Additionally, although the effect of dementia stage has not been studied explicitly [23], we expected support for withholding antibiotics to be higher for people closer to death. Conflicting results regarding the influence of respondent sociodemographic characteristics on endof-life decision-making, and the paucity of studies that have investigated support for CDS and MAID as potential correlates, precluded formulating a priori hypotheses regarding the associations of these factors with attitudes toward antibiotics in the presence of dementia [24, 27, 51-53].

\section{Methods}

\section{Study design, target populations, and sampling}

The data originate from an anonymous vignette-based survey designed to elicit the views of four groups of Quebec stakeholders (senior citizens, family caregivers, nurses and physicians) on end-of-life care options in the presence of dementia. Details of the survey have been published elsewhere [54]. Briefly, the four population-specific surveys were conducted consecutively from September 2016 to December 2017. Survey packages were mailed to 621 community-dwelling adults aged 65 and over, randomly sampled from the provincial health insurance database. Family caregivers $(n=471)$ were reached through regional Alzheimer Societies, whereas random lists of nurses $(n=514)$ and physicians $(n=653)$ likely to be involved in dementia care were provided by their professional associations. Sample sizes were established a priori, based on expected participation rates [54]. Respondents could provide their answers on the paper version of the questionnaire or access it on online using a single-use, personal access code. Following reminders sent two and nine weeks after the first mailing, 1184 of the 2259 sampled individuals returned the survey questionnaire. Excluding 134 persons who self-identified as non-eligible, the overall response rate was $49.4 \%$ (seniors $54 \%$, caregivers $69 \%$, nurses $59 \%$, physicians $25 \%$ ).

\section{Survey questionnaire}

The questionnaire began with the list of the eligibility criteria for MAID, and ended with questions aimed at describing survey participants. In between was a series of vignettes designed to elicit respondents' attitudes toward end-of-life care options (see Additional file 1: Survey items used in this paper). The vignettes feature a 75-year-old hypothetical woman, Mrs. Jackson, who has recently been diagnosed with Alzheimer disease. Following discussions with her treating physician and close relatives, Mrs. Jackson has documented her wishes for when she is no longer able to make healthcare decisions 
for herself. In writing, she has refused all life-prolonging interventions and explicitly requested that a doctor end her life when she no longer recognizes her loved ones. In the next vignettes, Mrs. Jackson, now lacking decisional capacity, has evolved to the advanced and then to the terminal stage of her illness. At the advanced stage, she is described as likely having several more years to live, while at the terminal stage, she is believed to be at the end of her life. At both stages, respondents were asked to rate the extent to which they found it acceptable (1) that the current legislation be changed to allow a doctor to grant Mrs. Jackson's request for MAID, and (2) that antibiotics be withheld from Mrs. Jackson should she develop a life-threatening infection. At the terminal stage only, respondents were further asked their attitudes toward deeply sedating the patient continuously until death to relieve her persistent distress. Responses were provided on a 5-point scale, ranging from totally unacceptable to totally acceptable.

\section{Statistical analysis}

Respondent characteristics and attitudes are summarized using means, standard deviations or percentages, depending on the measurement scale. To ensure adequate cell sizes for comparative analyses, answers to attitudinal items were dichotomized, comparing respondents who considered a practice to be acceptable in a given scenario (somewhat or totally) with those who did not. We used the generalized estimating equation (GEE) approach to investigate whether dementia stages, stakeholder groups, sociodemographic characteristics, and support for CDS and MAID, were related to attitudes toward antibiotics [55]. Modelling began by testing the statistical significance of the group-by-stage interaction to determine whether subsequent analyses had to be conducted separately for the advanced and terminal stages of dementia. Reported $p$-values are two-sided. GEE results are described using odds ratios (ORs) and 95\% confidence intervals (CIs). Data analysis was carried out using IBM SPSS for Windows, version 25.

\section{Results}

Respondent characteristics and support for MAID and CDS Respondent characteristics measured in all four stakeholder groups, and support for MAID and CDS in the context of dementia, are shown in Table 1 . Average age ranges from 49 years among physicians to 73 among seniors. Women outnumber men in all four groups, with percentages ranging from $53 \%$ among seniors to $82 \%$ among nurses. Reflecting the gradual secularization of the province of Quebec since the 1960s, average scores on the index of religiosity were relatively low [56], especially among physicians. Between 60 and $70 \%$ of respondents had cared for a dying relative or friend, and less than half had recorded their own healthcare wishes in the event of incapacity. As previously reported [57], at the terminal stage, support for extending MAID to the patient was relatively high in all four groups, from $71 \%$ among physicians to $91 \%$ among family caregivers, and always higher than at the advanced stage. At the terminal stage, support for MAID was higher than for CDS among seniors, caregivers and nurses, whereas no difference was found among physicians. In other words, Canadian stakeholders reported being less comfortable with a currently lawful end-of-life practice (CDS) than with one that is not (MAID in the context of decisional incapacity). Although not the topic of this paper, this finding has implications for MAID laws which, ultimately, should reflect societal values [29].

\section{Attitudes toward withholding antibiotics, and correlates}

Figure 1 shows the extent to which respondents found it acceptable to withhold antibiotic therapy from the depicted patient, stratified by stakeholder group and dementia stage. In the context where the patient has refused in writing all medical interventions that could prolong her life after she is no longer able to make healthrelated decisions (see Additional file 1: Survey items used in this paper), the acceptability of withholding antibiotics was relatively high in all four stakeholder groups. Combining somewhat acceptable and totally acceptable responses, support ranged from $75 \%$ among seniors and caregivers at the advanced stage, to $98 \%$ among physicians at the terminal stage. Visual inspection of Fig. 1 suggests some effect of the dementia stage, which was confirmed by a statistically significant group-by-stage interaction $(p=0.003)$. Accordingly, subsequent analyses were carried out separately for the advanced and terminal stages.

Table 2 shows the results of investigating the associations between various factors and respondents' attitudes toward withholding antibiotics from the depicted patient, at the advanced stage of dementia. No differences in support for withholding antibiotics were detected between caregivers and seniors, nor between nurses and seniors, while the odds of physicians' supporting this practice were 15 times higher than among seniors $(p<0.001)$. Gender and level of religiosity were both found to be associated with attitudes toward withholding antibiotics, but not age, having accompanied a dying loved one, or having an advance directive. Compared to men, women had 1.5 higher odds of supporting this practice, whereas a 5 -point decrease in the index of religiosity (pointing to less religious respondents) increases by $27 \%$ the odds of finding it acceptable to withhold antibiotics 
Table 1 Respondent characteristics and attitudes toward continuous deep sedation and medical assistance in dying for a person with dementia who lacks decisional capacity ${ }^{a}$

\begin{tabular}{|c|c|c|c|c|}
\hline Characteristics and attitudes & Seniors $n=317$ & Caregivers $n=306$ & Nurses $n=291$ & Physicians $n=136$ \\
\hline Age (in years) & $72.7 \pm 5.9$ & $65.9 \pm 11.4$ & $51.7 \pm 9.1$ & $49.2 \pm 12.5$ \\
\hline Gender (female) & $53 \%$ & $72 \%$ & $82 \%$ & $60 \%$ \\
\hline Religiosity ${ }^{b}$ & $5.9 \pm 4.2$ & $5.9 \pm 4.0$ & $5.3 \pm 3.6$ & $3.5 \pm 3.5$ \\
\hline $\begin{array}{l}\text { Have accompanied a dying relative or friend through the dying } \\
\text { process }\end{array}$ & $70 \%$ & $67 \%$ & $69 \%$ & $60 \%$ \\
\hline Have themselves completed an advance directive & $44 \%$ & $43 \%$ & $34 \%$ & $49 \%$ \\
\hline \multicolumn{5}{|c|}{ Find it acceptable (somewhat or totally) to extend medical assistance in dying to the person with dementia } \\
\hline At the advanced stage & $76 \%$ & $68 \%$ & $53 \%$ & $45 \%$ \\
\hline At the terminal stage & $90 \%$ & $91 \%$ & $83 \%$ & $71 \%$ \\
\hline $\begin{array}{l}\text { Find it acceptable (somewhat or totally) to deeply sedate the person } \\
\text { with dementia until death, at the terminal stage }\end{array}$ & $79 \%$ & $69 \%$ & $70 \%$ & $68 \%$ \\
\hline
\end{tabular}

\footnotetext{
${ }^{a}$ Data shown are means \pm standard deviations or percentages derived from valid cases. Few data were missing: from 1 for gender to 23 for one or more of the four items involved in deriving the religiosity index

${ }^{b}$ The religiosity index is derived by combining answers to four questions developed by Statistics Canada for the General Social Survey [56]. Total scores range from 0 to 13 and are interpreted in three broad categories: low $(0-5)$, moderate $(6-10)$, and high $(11-13)$
}

from the patient $(\mathrm{OR}=1.27)$. Attitudes toward allowing MAID at the advanced stage of dementia were also associated with the outcome. Proponents had 3.5 higher odds of finding it acceptable that antibiotics be withheld, compared to opponents.

At the terminal stage (cf. Table 3), nurses and physicians were more likely than seniors to support the withholding of antibiotics $(\mathrm{OR}=3.0, p=0.003$, and $\mathrm{OR}=28.2, p<0.001$, respectively), with no difference found between caregivers and seniors. In the context of terminal dementia, religiosity is the only sociodemographic characteristic found to be associated with attitudes toward the use of antibiotics. Support for MAID and support for CDS are also associated with the outcome, with positive attitudes toward these practices increasing the odds of being in favour of withholding antibiotics $(\mathrm{OR}=3.2$ and 5.2 , respectively, $p<0.001$ ). Accounting for other influential factors, the odds of supporting the withholding of antibiotics from a person with dementia who lacks decisional capacity is thus higher among stakeholders who also support extending MAID to this population (Tables 2 and 3 ) or relying on CDS to relieve the person's suffering when death is imminent (Table 3).

\section{Discussion}

To the best of our knowledge, this study is the first to investigate variability across dementia stages and stakeholder groups in the acceptability of withholding antibiotics from a person with dementia who lacks decisional capacity, in the context where she has refused all life-prolonging interventions and explicitly requested that a doctor end her life when she no longer recognizes her loved ones. Faced with this decision, the vast majority of our respondents would likely decide against initiating antibiotics (cf. Figure 1). Still, substantial minorities, mainly among senior citizens, family caregivers and nurses, found withholding antibiotics unacceptable, even at the terminal stage and with some knowledge of the patient's wishes. Like others $[51,53]$, we found religiosity to exert some influence on attitudes toward end-of-life care, with the least religious of our respondents being more likely to support withholding antibiotics from the patient, at both stages of dementia. We also found positive attitudes toward MAID and CDS to increase the likelihood of finding it acceptable to withhold antibiotics. Regarding MAID, our finding concurs with those of Hinkka et al. [51], who found, among Finnish physicians, support for "active euthanasia" to be associated with a preference to withhold antibiotics from a terminally ill cancer patient.

The person featured in our vignettes wanted to avoid prolonged dementia, either by the withholding of a potentially life-prolonging intervention or by MAID (should it be legalized). According to our findings, which revealed substantial variability in the acceptability of withholding antibiotics from the now-incapacitated person, whether her wish is honored could depend on who has decision-making authority for or influence over medical decisions. This variability can be explained by several factors.

First, although not unusual, Mrs. Jackson's instructions for future care are not explicit about antibiotic therapy for pneumonia, requiring some interpretation. Most physicians and a significant number of nurses, perhaps more knowledgeable about antibiotics, may have interpreted the person's refusal of all life-prolonging interventions 

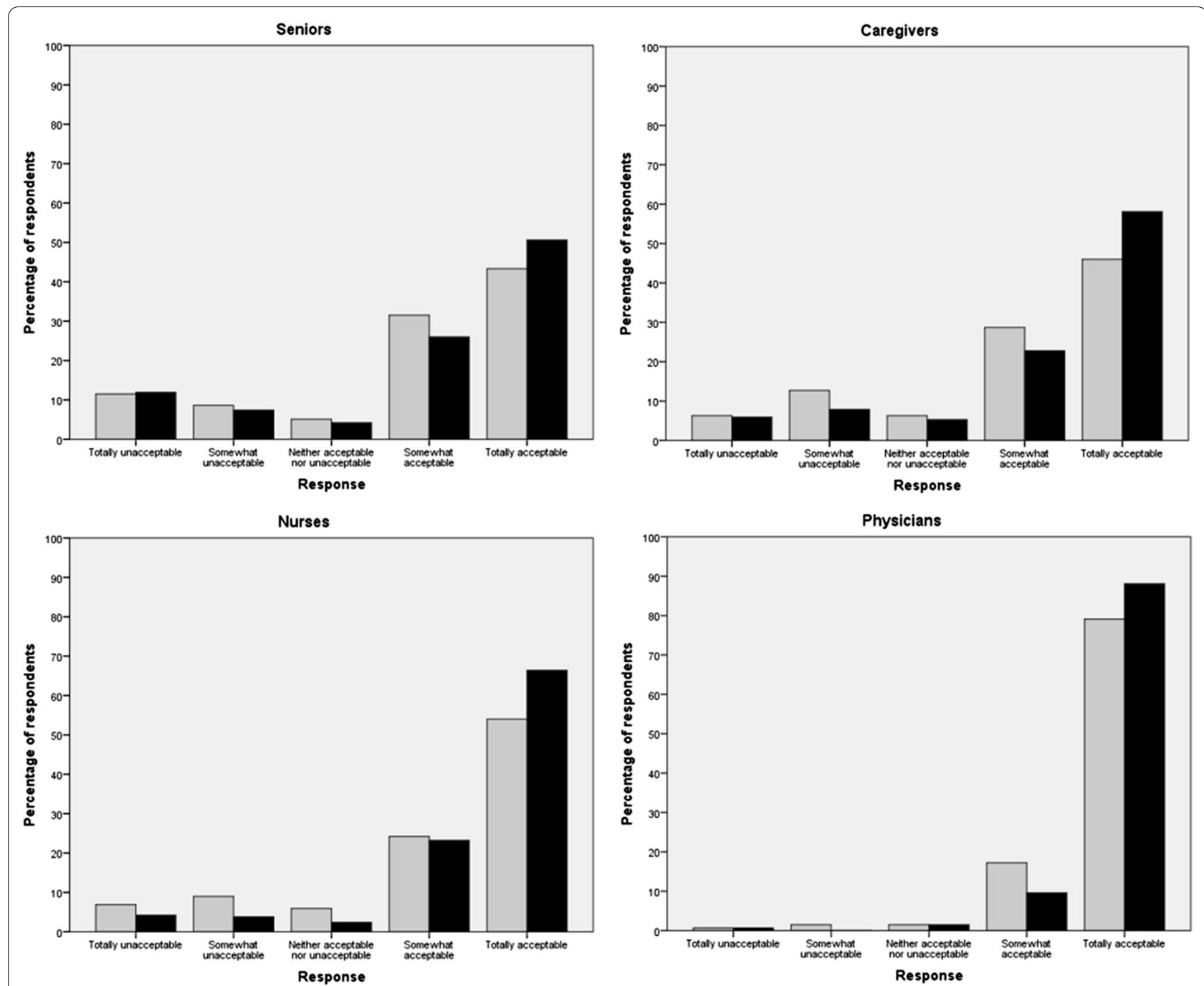

Fig. 1 Acceptability of withholding antibiotics from a person with dementia who lacks decisional capacity, at the advanced (in grey) and terminal (in black) stages, by stakeholder group

to include antibiotic therapy, while many senior citizens and family caregivers may not have seen antibiotics as life-prolonging. Lay respondents' answers to the vignettes may have differed had Mrs. Jackson been more specific. Forms for accepting or refusing medical interventions for times of incapacity, such as advance medical directives in Quebec, would benefit from expressly addressing antibiotic therapy, given the high prevalence of infections in later stages of dementia. Having observed that support for end-of-life practices varies between dementia stages, such forms could also be more dementia-specific. This could be achieved by describing the main dementia stages (e.g., mild, moderate, severe) and allowing the person to choose different options of care for each of these stages $[58,59]$. Better still, because documentation of wishes for end-of-life care without communication may not be effective, wishes should be discussed within advance care planning $(\mathrm{ACP})^{6}$ conversations between the person with dementia, their relatives and healthcare professionals $[61$, 62].

Second, respondents' answers may have been influenced by a projection bias, which leads people to choose care options that reflect what they would want for themselves rather than preferences previously expressed by the person who now lacks decisional capacity [63, 64].

\footnotetext{
${ }^{6} \mathrm{ACP}$ is "a process that supports adults at any age or stage of health in understanding and sharing their personal values, life goals and preferences regarding future medical care" [60]. ACP can include conversations with people likely to be involved in their future care (e.g., treating physician, close relatives) and documentation of values and preferences for care.
} 
Table 2 Multivariable GEE results from investigating factors related to finding it acceptable (somewhat or totally) to withhold antibiotics from a person with dementia who lacks decisional capacity, at the advanced stage

\begin{tabular}{|c|c|c|c|}
\hline & OR & $p$-value & $95 \% \mathrm{Cl}$ \\
\hline \multicolumn{4}{|l|}{ Group effect } \\
\hline Senior citizens (reference) & 1 & & \\
\hline Family caregivers & 0.98 & 0.914 & $0.6-1.5$ \\
\hline Nurses & 1.6 & 0.115 & $0.9-2.8$ \\
\hline Physicians & 15.1 & $<0.001$ & $4.9-46.4$ \\
\hline Age & 1.0 & 0.858 & $0.98-1.02$ \\
\hline \multicolumn{4}{|l|}{ Gender } \\
\hline Male (reference) & 1 & & \\
\hline Female & 1.5 & 0.017 & $1.1-2.2$ \\
\hline Religiosity & 0.95 & 0.032 & $0.9-1.0$ \\
\hline $\begin{array}{l}\text { Have accompanied a dying relative or } \\
\text { friend through the dying process }\end{array}$ & 1.1 & 0.515 & $0.8-1.6$ \\
\hline $\begin{array}{l}\text { Have themselves completed an advance } \\
\text { directive }\end{array}$ & 1.3 & 0.153 & $0.9-1.8$ \\
\hline \multicolumn{4}{|c|}{$\begin{array}{l}\text { Find it acceptable (somewhat or totally) to extend medical assistance in } \\
\text { dying to the person with dementia, at the advanced stage }\end{array}$} \\
\hline No (reference) & 1 & & \\
\hline Yes & 3.5 & $<0.001$ & $2.5-5.0$ \\
\hline
\end{tabular}

Bold is used to highlight $p$-values that are smaller than 0.05

Table 3 Multivariable GEE results from investigating factors related to finding it acceptable (somewhat or totally) to withhold antibiotics from a person with dementia who lacks decisional capacity, at the terminal stage

\section{OR $p$-value $95 \% \mathrm{Cl}$}

\section{Group effect}

Senior citizens (reference)

Family caregivers

Nurses

Physicians

Age

Gender

Male (reference)

Female

Religiosity

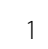

$\begin{array}{lll}1.4 & 0.157 & 0.9-2.3\end{array}$

$\begin{array}{lll}3.0 & \mathbf{0 . 0 0 3} & 1.5-6.0\end{array}$

$28.2<0.001 \quad 6.0-132.5$

$\begin{array}{lll}1.0 & 0.260 & 0.97-1.01\end{array}$

$\begin{array}{llll}\text { Have accompanied a dying relative or } & 0.86 & 0.475 & 0.6-1.3\end{array}$ friend through the dying process

Have themselves completed an advance $\begin{array}{llll}1.4 & 0.124 & 0.9-2.1\end{array}$ directive

Find it acceptable (somewhat or totally) to extend medical assistance in dying to the person with dementia, at the terminal stage

No (reference)

Yes

$3.2<\mathbf{0 . 0 0 1} \quad 1.9-5.4$

Find it acceptable (somewhat or totally) to deeply sedate the person with dementia, at the terminal stage

No (reference)

Yes

$5.2<0.001 \quad 3.4-7.9$
Third, at the advanced stage, where the patient is depicted as likely having several more years to live and not being in distress, some respondents may have felt that her life was still worth living, prioritizing what they believed was in her best interests at the time rather than her previously expressed wishes. At the advanced stage, the percentages of senior citizens and family caregivers against withholding antibiotics are similar to those against extending MAID to the person with dementia (cf. Table 1). This reinforces the impression that some respondents were not comfortable with a decision that would hasten death at this stage of the dementia trajectory and in the absence of distress.

Such considerations are less likely to explain lay respondents' reluctance to withhold antibiotics at the terminal stage, where the person was depicted as being at the end of her life and in distress. Here, not recognizing dementia as a terminal condition, or not viewing pneumonia as part of a "natural death" for someone with severe dementia, are plausible explanations. In focus groups with U.S. family members of nursing home residents with moderate to very severe dementia, Forbes et al. [50] found that in the absence of a clear understanding of the dying trajectory, family members felt compelled to treat "treatable conditions" such as pneumonia, even in late-stage dementia. Fear of abandoning the patient and of making the wrong decision have also been cited by families as reasons for providing treatment that professionals may consider futile $[25,52,65]$.

\section{Implications for practice}

The explanations proposed above underscore the importance of explaining the risks, burdens and benefits of care options to patients and their family members, and exploring patients' underlying values and preferences for comfort or life-prolonging care [66]. Initiated in the earlier stages of dementia, these ACP conversations would aim at helping the patient make fully-informed decisions regarding future care, preparing surrogate decision-makers for their role (which could include deciding whether antibiotics should be initiated or withheld) and increasing the likelihood that the patient's wishes will later be honored [61, 62]. A booklet developed in Canada for informing families on the course of dementia, possible complications, therapeutic options and decision-making (e.g., regarding antibiotics) could prove useful in achieving these objectives [67]. Available in several languages, the booklet could also be used as a complementary educational tool for healthcare professionals $[68,69]$. As this booklet targets family members and not persons with dementia, it does not contain a form to document wishes for times of incapacity. However, ACP booklets with

Bold is used to highlight $p$-values that are smaller than 0.05 
sample plans are available in several countries and languages [e.g., 70, 71].

\section{Limitations and strengths}

Our study has limitations that warrant comment. First, response rates and sample sizes are relatively large, except for physicians. As a result, ORs are less precise for this stakeholder group. Moreover, cell size considerations led us to collapse response options for analysis, thereby losing some information. Larger samples would allow more refined analyses. Second, family caregivers of persons with dementia who are not members of Alzheimer Societies could not be reached through our recruitment strategy. Moreover, as for any survey, individuals who elected to complete the questionnaire may differ from non-respondents. In particular, our samples may have included people with a keen interest in MAID, whether in favour or opposed. MAID was a hot topic in Canada at the time of the survey, and still is. Third, findings are based on samples from Quebec, potentially affecting generalizability, especially to jurisdictions with different legislation governing end-of-life care for incapacitated patients. Fourth, vignettes are valuable for comparing opinions on controversial topics, but they are limited in the amount of information they can convey. In real-life situations, decision-makers would likely have more knowledge of the patient than that provided in a fictitious case description. Despite being defined in the survey questionnaire, the terms advanced and terminal that we used to describe dementia stages may have been interpreted differently by some respondents. Fifth, respondents were asked to rate the acceptability of different care options, and not what decision they would have made in the depicted situations. The vignettes featured a third party, and not a loved one or themselves. We do not know whether framing the questions differently would have changed our findings. Also, the decision to provide or withhold antibiotics for a life-threatening pneumonia as inferred from respondents' acceptability levels could differ from the decision that would actually be made in practice, as the latter would likely benefit from healthcare professionals' and family members' discussing the benefits and burdens of the various care options [72]. Lastly, the survey was conducted 4 years ago, and end-of-life care practices evolve rapidly. A follow-up survey would be worth doing, as well as focus groups to deepen our understanding of stakeholders' preferences for one practice over others.

Our study also has strengths. These include the random selection of potential respondents belonging to relevant stakeholder groups; the use of the same set of vignettes across groups, enabling direct comparisons of their views; attitudes explored at two distinct stages along the dementia trajectory; and analyses that included respondents' attitudes toward other end-of-life medical interventions, in addition to their sociodemographic characteristics.

\section{Conclusions}

Using a fictitious person with dementia who had refused in writing all life-prolonging interventions and requested MAID, we found relatively high support for withholding antibiotics in the event of a life-threatening infection, but also variability across stakeholder groups. Physicians consider withholding antibiotics more acceptable than other stakeholders. Higher support for this practice was also found among less religious respondents and those supporting MAID and CDS in the context of dementia. Professionals caring for patients with dementia should acknowledge differences in attitudes toward end-of-life care options, which may complicate decision-making at the end of life. Discussions about end-of-life care goals and options, including the use of possibly life-prolonging treatments such as antibiotics, with patients and their loved ones early in the dementia trajectory could help people with dementia make informed choices about future care and clearly communicate their wishes about such care, in addition to helping surrogate decision-makers to honour those wishes.

\section{Abbreviations}

CDS: Continuous deep sedation; MAID: Medical assistance in dying; GEE: Generalized estimating equation; OR: Odds ratio; Cl: Confidence interval; ACP: Advance care planning.

\section{Supplementary Information}

The online version contains supplementary material available at https://doi. org/10.1186/s12910-021-00689-1.

Additional file 1. Survey items used in this paper.

\section{Acknowledgements}

Special thanks are extended to all older adults, informal caregivers, nurses, and physicians who took the time to fill out the questionnaire. We also thank the anonymous reviewers for their helpful comments on the initial version of this paper.

\section{Authors' contributions}

GB and LVDB formulated the research questions. All authors were involved in the development of the survey questionnaire, contributing specific expertise in questionnaire design (GB, LVDB, LT), legal aspects of end-of-life care (JD) and clinical management of patients with end-stage dementia (MA). GB wrote the first draft of the paper, which was critically reviewed by all coauthors. LT conducted the statistical analyses. All authors have read and approved the final version of the paper.

\section{Funding}

The study was funded by an unrestricted grant from the Alzheimer Society of Canada (Grant \# 16 11). The granting agency approved the study objectives 
and design, but was not involved in data collection, analysis or interpretation, nor in the decision to publish study findings.

\section{Availability of data and materials}

The dataset used for the current paper is available from the corresponding author on reasonable request.

\section{Declarations}

\section{Ethics approval and consent to participate}

Ethics approval was granted by the Research Ethics Board of the CIUSSS de I'Estrie-CHUS (file \#2016-623). The survey was carried out in accordance with the Canadian Tri-Council Policy Statement: Ethical Conduct for Research Involving Humans - TCPS 2 (2018). Consent information was provided on the cover page of the questionnaire, and consent inferred from sampled individuals who returned the questionnaire.

\section{Consent for publication}

Not applicable.

\section{Competing interests}

The authors declare that they have no competing interests.

\section{Author details}

${ }^{1}$ Department of Community Health Sciences, Faculty of Medicine and Health Sciences, Université de Sherbrooke, Sherbrooke, Canada. ${ }^{2}$ Research Centre On Aging, CIUSSS de I'Estrie - CHUS, 1036 South Belvedere Street, Sherbrooke J1H 4C4, Canada. ${ }^{3}$ VUB-UGhent End-of-Life Care Research Group, Vrije Universiteit Brussel (VUB), Brussels, Belgium. ${ }^{4}$ Schulich School of Law and Faculty of Medicine, Dalhousie University, Halifax, Canada. ${ }^{5}$ Department of Family Medicine, Faculty of Medicine and Health Sciences, Université de Sherbrooke, Sherbrooke, Canada.

Received: 14 June 2021 Accepted: 23 August 2021

Published online: 06 September 2021

\section{References}

1. Arcand M. End-of-life issues in advanced dementia. Part 2: Management of poor nutritional intake, dehydration, and pneumonia. Can Fam Physician. 2015:61:337-41.

2. van der Maaden T, van der Steen JT, de Vet HCW, Hertogh CMPM, Koopmans RTCM. Prospective observations of discomfort, pain, and dyspnea in nursing homes residents with dementia and pneumonia. J Am Med Dir Assoc. 2016:17:128-35.

3. Miranda R, van der Steen JT, Smets T, Van den Noortgate N, Deliens L, Payne S, et al. Comfort and clinical events at the end of life of nursing home residents with and without dementia: The six-country epidemiological PACE study. Int J Geriatr Psychiatry. 2020;35:719-27.

4. Mitchell SL. Care of patients with advanced dementia. http://www.uptod ate.com. Accessed 15 June 2020

5. Givens JL, Kiely DK, Carey K, Mitchell S. Healthcare proxies of nursing home residents with advanced dementia: Decisions they confront and their satisfaction with decision-making. J Am Geriatr Soc. 2009;57:1149-55.

6. Biola H, Sloane PD, Williams CS, Daaleman TP, Zimmerman S. Preferences versus practice: Life-prolonging treatments in last months of life in longterm care. J Am Med Dir Assoc. 2010;11:42-51.

7. Bryant J, Sellars M, Sinclair C, Detering K, Buck K, Waller A, et al. Inadequate completion of advance care directives by individuals with dementia: National audit of health and aged care facilities. BMJ Support Palliat Care. 2021. https://doi.org/10.1136/bmjspcare-2020-002767.

8. Fetherstonhaugh D, McAuliffe L, Bauer M, Shanley C. Decision-making on behalf of people living with dementia: how do surrogate decision-makers decide? J Med Ethics. 2017:43:35-40.

9. Yadav KN, Gabler NB, Cooney E, Kent S, Kim J, Herbst N, et al. Approximately one in three US adults completes any type of advance directive for end-of-life care. Health Aff. 2017;36:1244-51.
10. Wendler D. The theory and practice of surrogate decision-making. Hastings Cent Rep. 2017:47:29-31.

11. Givens JL, Jones RN, Shaffer ML, Kiely DK, Mitchell SL. Survival and comfort after treatment of pneumonia in advanced dementia. Arch Intern Med. 2010:170:1102-7.

12. Rozzini R, Bellelli G, Trabucchi M. Antibiotic treatment for patients affected by severe dementia and pneumonia. Arch Intern Med. 2011;171:93-4

13. Parsons $C$, van der Steen JT. Antimicrobial use in patients with dementia: current concerns and future recommendations. CNS Drugs. 2017:31:433-8

14. van der Steen JT, Ooms ME, van der Wal G, Ribbe MW. Pneumonia: the demented patient's best friend? Discomfort after starting or withholding antibiotic treatment. J Am Geriatr Soc. 2002:50:1681-8.

15. Szafara KL, Kruse RL, Mehr DR, Ribbe MW, van der Steen JT. Mortality following nursing home-acquired lower respiratory infection: LRI severity, antibiotic treatment, and water intake. J Am Med Dir Assoc. 2012:13:376-83.

16. Marcus E-L, Clarfield M, Moses AE. Ethical issues relating to the use of antimicrobial therapy in older adults. Clin Infect Dis. 2001;33:1697-705.

17. Schwaber MJ, Carmeli Y. Antibiotic therapy in the demented elderly population. Redefining the ethical dilemma. Arch Intern Med. 2008;168:349-50

18. Leibovici L, Paul M. Ethical dilemma in antibiotic treatment: Focus on the elderly. Clin Microbiol Infect. 2015;21:27-9.

19. Reyniers T, Deliens L, Pasman HR, Morin L, Addington-Hall J, Frova L, et al. International variation in place of death of older people who died from dementia in 14 European and non-European countries. J Am Med Dir Assoc. 2015:16:165-71.

20. Honinx E, van Dop N, Smets T, Deliens L, Van den Noortgate N, Froggatt $K$, et al. Dying in long-term care facilities in Europe: the PACE epidemiological study of deceased residents in six countries. BMC Public Health. 2019;19:1199. https://doi.org/10.1186/s12889-019-7532-4.

21. van der Steen JT, Muller MT, Ooms ME, van der Wal G, Ribbe MW. Decisions to treat or not to treat pneumonia in demented psychogeriatric nursing home patients: development of a guideline. J Med Ethics. 2000;26:114-20.

22. van der Steen JT, Pasman HRW, Ribbe MW, van der Wal G, OnwuteakaPhilipsen BD. Discomfort in dementia patients dying from pneumonia and its relief by antibiotics. Scand J Infect Dis. 2009:41:143-51.

23. van der Maaden T, Hendriks SA, de Vet HCW, Zomerhuis MT, Smalbrugge $\mathrm{M}$, Jansma EP, et al. Antibiotic use and associated factors in patients with dementia: a systematic review. Drugs Aging. 2015;32:43-56.

24. Hinkka H, Kosunen E, Lammi EK, Metsänoja R, Puustelli A, KellokumpuLehtinen P. Decision making in terminal care: a survey of Finnish doctors' treatment decisions in end-of-life scenarios involving a terminal cancer and a terminal dementia patient. Palliat Med. 2002;16:195-204.

25. Caron C, Griffith J, Arcand M. End-of-life decision making in dementia. Dementia. 2005:4:113-36

26. Benoit SR, Nsa W, Richards CL, Bratzler DW, Shefer AM, Steele LM, et al. Factors associated with antimicrobial use in nursing homes: a multilevel model. J Am Geriatr Soc. 2008;56:2039-44.

27. Torke AM, Moloney R, Siegler M, Abalos A, Alexander GC. Physicians'views on the importance of patient preferences in surrogate decision making. J Am Geriatr Soc. 2010;58:533-8.

28. van Buul LW, van der Steen JT, Doncker SM, Achterberg WP, Schellevis FG, Veenhuizen RB, et al. Factors influencing antibiotic prescribing in longterm care facilities: a qualitative in-depth study. BMC Geriatr. 2014;14:136. https://doi.org/10.1186/1471-2318-14-136.

29. White BP, Willmott L, Williams G, Cartwright C, Parker M. The role of law in decisions to withhold and withdraw life-sustaining treatrment from adults who lack capacity: a cross sectional study. J Med Ethics. 2017:43:327-33.

30. Molloy DW, Guyatt GH, Alemayehu E, Mcllroy W, Willan A, Eisemann M, et al. Factors affecting physicians' decisions on caring for an incompetent elderly patient: an international study. Can Med Assoc J. 1991;145:947-52.

31. van der Steen JT, Kruse RL, Ooms ME, Ribbe MW, van der Wal G, Heintz $\mathrm{LL}$, et al. Treatment of nursing home residents with dementia and lower respiratory tract infection in the United States and the Netherlands: an ocean apart. J Am Geriatr Soc. 2004:52:691-9. 
32. Helton MR, van der Steen JT, Daaleman TP, Gamble GR, Ribbe MW. A cross-cultural study of physician treatment decisions for demented nursing home patients who develop pneumonia. Ann Fam Med. 2006; $4: 221-7$

33. Honinx E, Van den Block L, Piers R, Van Kuijk SMJ, Onwuteaka-Philipsen BD, Payne SA, et al. Potentially inappropriate treatments at the end of life in nursing home residents: findings from the PACE cross-sectional study in six European countries. J Pain Symptom Manage. 2021;61:732-42.e1. https://doi.org/10.1016/j.jpainsymman.2020.09.001.

34. Anquinet L, Raus K, Sterckx S, Smets T, Deliens L, Rietjens JAC. Similarities and differences between continuous sedation until death and euthanasia - Professional caregivers' attitudes and experiences: a focus group study. Palliat Med. 2013;27:553-61.

35. Miccinesi G, Rietjens JAC, Deliens L, Paci E, Bosshard G, Nilstun T, et al. Continuous deep sedation: physicians' experiences in six European countries. J Pain Symptom Manage. 2006;31:122-9.

36. Putman MS, Yoon JD, Rasinski KA, Curlin FA. Intentional sedation to unconsciousness at the end of life: findings from a national physician survey. J Pain Symptom Manage. 2013;46:326-34.

37. Rys S, Mortier F, Deliens L, Bilsen J. The practice of continuous sedation until death in nursing homes in Flanders, Belgium: a nationwide study. J Am Geriatr Soc. 2014;62:1869-76.

38. Loizeau AJ, Cohen SM, Mitchell SL, Theill N, Eicher S, Martin M, Riese F. Physician and surrogate agreements with assisted dying and continuous deep sedation in advanced dementia in Switzerland. Neurodegener Dis. 2019;19:4-11.

39. Council of Canadian Academies. The State of Knowledge on Advance Requests for Medical Assistance in Dying. Ottawa: The Expert Panel Working Group on Advance Requests for MAID, Council of Canadian Academies, 2018.

40. Government of Canada. Bill C-14: An Act to amend the Criminal Code and to make related amendments to other Acts (medical assistance in dying). Ottawa: Government of Canada, 2016. https://laws-lois.justice.gc. ca/eng/annualstatutes/2016_3/fulltext.html. Accessed 20 May 2020.

41. Downie J. Bill C-7 will allow some Canadians suffering from dementia to make a request for MAID before the loss of decision-making capacity. Policy Options (2020). https://policyoptions.irpp.org/magazines/octob er-2020/medical-assistance-in-dying-bill-an-important-step-forward-forcanadians-with-dementia/. Accessed 03 January 2021.

42. Grant K. From dementia to medically assisted death: A Canadian woman's journey, and the dilemma of the doctors who helped. The Globe and Mail (2019). https://www.theglobeandmail.com/canada/article-from-demen tia-to-medically-assisted-death-a-canadian-womans-journey/. Accessed 03 January 2021.

43. CBC Radio. B.C. man is one of the first Canadians with dementia to die with medical assistance (2019). https://www.cbc.ca/radio/thesundaye dition/the-sunday-edition-for-october-27-2019-1.5335017/b-c-manis-one-of-the-first-canadians-with-dementia-to-die-with-medical-assis tance-1.5335025. Accessed 03 January 2021.

44. Frangou C. When assisted dying means you have to go before you're ready. The Guardian (2020). https://www.theguardian.com/society/2020/ mar/04/assisted-dying-maid-canada-leila-bell. Accessed 03 January 2021.

45. Government of Canada. Bill C-7. An Act to amend the Criminal Code (medical assistance in dying). Ottawa: Government of Canada, 2020. https://www.parl.ca/DocumentViewer/en/43-1/bill/C-7/first-reading. Accessed 18 May 2020.

46. Curateur public. Prepare your protection mandate. https://www.curateur. gouv.qc.ca/cura/en/ outils/publications/mon_mandat.html. Accessed 18 July 2021.

47. Gouvernement du Québec. Advance Medical Directives. https://www. quebec.ca/en/health/ health-system-and-services/end-of-life-care/ advance-medical-directives. Accessed 18 July 2021

48. Gouvernement du Québec. Act Respecting End-of-Life Care. https:// www.quebec.ca/en/ health/health-system-and-services/end-of-life-care/ act-respecting-end-of-life-care. Accessed 18 July 2021.

49. Gouvernement du Québec. Civil Code of Québec. http://legisquebec. gouv.qc.ca/en/showdoc/cs/ccq-1991. Accessed 18 July 2021.

50. Forbes S, Bern-Klug M, Gessert C. End-of-life decision making for nursing home residents with dementia. J Nurs Scholarsh. 2000;32:251-8.
51. Hinkka H, Kosunen E, Metsänoja R, Lammi U-K, Kellokumpu-Lehtinen P. Factors affecting physicians' decisions to forgo life-prolonging treatments in terminal care. J Med Ethics. 2002;28:109-14.

52. Willmott L, White B, Gallois C, Parker M, Graves N, Winch S, et al. Reasons doctors provide futile treatment at the end of life: a qualitative study. J Med Ethics. 2016;42:496-503.

53. van Wijmen MP, Pasman HR, Widdershoven GA, Onwuteaka-Philipsen BD. Continuing or forgoing treatment at the end of life? preferences of the general public and people with an advance directive. J Med Ethics. 2015;41:599-606

54. Bravo G, Rodrigue C, Thériault V, Arcand M, Downie J, Dubois M-F, et al. Should medical aid in dying be extended to incompetent patients with dementia? Research protocol of a survey among four groups of stakeholders from Quebec. Canada JMIR Res Protoc. 2017;6: e208. https://doi. org/10.2196/resprot.8118.

55. Agresti A. Categorical data analysis. 2nd ed. Hoboken, NJ: Wiley; 2002.

56. Clark W, Schellenberg G. Who's religious? Catalogue No: 11-008. Statistics Canada: Canadian Social Trends; 2006.

57. Bravo G, Trottier L, Rodrigue C, Arcand M, Downie J, Dubois M-F, et al. Comparing the attitudes of four groups of stakeholders from Quebec, Canada, toward extending medical aid in dying to incompetent patients with dementia. Int J Geriatr Psychiatry. 2019;34:1078-86.

58. Gaster B, Larson EB, Curtis JR. Advance directives for dementia. Meeting a unique challenge JAMA. 2017;318:2175-6.

59. Advance directive for dementia. http://dementia-directive.org. Accessed 17 July 2021.

60. Sudore RL, Lum HD, You JJ, Hanson LC, Meier DE, Pantilat SZ, et al. Defining advance care planning for adults: a consensus definition from a multidisciplinary Delphi panel. J Pain Symptom Manage. 2017;53:821-32.

61. Piers R, Albers G, Gilissen J, De Lepeleire J, Steyaert J, Van Mechelen W, et al. Advance care planning in dementia: recommendations for healthcare professionals. BMC Palliat Care. 2018;17:88. https://doi.org/10.1186/ s12904-018-0332-2.

62. Wendrich-van Dael A, Bunn F, Lynch J, Pivodic L, Van den Block L, Goodman C. Advance care planning for people living with dementia: an umbrella review of effectiveness and experiences. Int J Nurs Stud. 2020;107: 103576. https://doi.org/10.1016/j.jinurstu.2020.103576.

63. Bravo G, Sene M, Arcand M. Surrogate inaccuracy in predicting older adults' desire for life-prolonging interventions in the event of decisional incapacity: is it due in part to erroneous quality-of-life assessments? Int Psychogeriatr. 2017;29:1061-8.

64. Lamahewa K, Mathew R, lliffe S, Wilcock J, Manthorpe J, Sampson EL, et al. A qualitative study exploring the difficulties influencing decision making at the end of life for people with dementia. Health Expect. 2018;21:118-27.

65. Fetherstonhaugh D, McAuliffe L, Shanley C, Bauer M, Beattie E. “Did I make the right decision?"The difficult and unpredictable journey of being a surrogate decision maker for a person living with dementia. Dementia. 2019;18:1601-14

66. Arcand M. End-of-life issues in advanced dementia: Part 1: goals of care, decision-making process, and family education. Can Fam Physician. 2015;61:330-4.

67. Arcand M, Monette J, Monette M, Sourial N, Fournier L, Gore B, et al. Educating nursing home staff about the progression of dementia and the comfort care option: impact on family satisfaction with end-of-life care. J Am Med Dir Assoc. 2009;10:50-5.

68. van der Steen JT, Arcand M, Toscani F, de Graas T, Finetti S, Beaulieu M, et al. A family booklet about comfort care in advanced dementia: threecountry evaluation. J Am Med Dir Assoc. 2011;13:368-75.

69. Arcand M, Brazil K, Nakanishi M, Nakashima T, Alix M, Desson J-F, et al. Educating families about end-of-life care in advanced dementia: acceptability of a Canadian family booklet to nurses from Canada, France, and Japan. Int J Palliat Nurs. 2013;19:67-74.

70. Advance Care Planning Canada. Advance Care Planning Workbook. http://www.advancecareplanning.ca/my-plan/. Accessed 18 July 2021.

71. Institute for Healthcare Improvement. The Conversation Project. Conversation Starter Guide for Caregivers of People with Alzheimer's or Other Forms of Dementia. http://theconversationproject.org. Accessed 18 July 2021. 
72. Lord K, Livingston G, Cooper C. A systematic review of barriers and facilitators to and interventions for proxy decision-making by family carers of people with dementia. Int Psychogeriatr. 2015;27:1301-12.

\section{Publisher's Note}

Springer Nature remains neutral with regard to jurisdictional claims in published maps and institutional affiliations.
Ready to submit your research? Choose BMC and benefit from:

- fast, convenient online submission

- thorough peer review by experienced researchers in your field

- rapid publication on acceptance

- support for research data, including large and complex data types

- gold Open Access which fosters wider collaboration and increased citations

- maximum visibility for your research: over $100 \mathrm{M}$ website views per year

At BMC, research is always in progress.

Learn more biomedcentral.com/submissions 